\title{
Bur open Explaining the barriers to and tensions in delivering effective healthcare in UK care homes: a qualitative study
}

\author{
Isabella Robbins, ${ }^{1}$ Adam Gordon, ${ }^{1}$ Jane Dyas, ${ }^{2}$ Philippa Logan, ${ }^{1}$ John Gladman ${ }^{1}$
}

To cite: Robbins I, Gordon A, Dyas J, et al. Explaining the barriers to and tensions in delivering effective healthcare in UK care homes: a qualitative study. BMJ Open 2013;3:e003178.

doi:10.1136/bmjopen-2013003178

- Prepublication history and additional material for this papers are available online. To view these files please visit the journal online (http://dx.doi.org/10.1136/ bmjopen-2013-003178).

Received 8 May 2013 Revised 6 June 2013 Accepted 17 June 2013

This final article is available for use under the terms of the Creative Commons Attribution Non-Commercial 3.0 Licence; see http://bmjopen.bmj.com

For numbered affiliations see end of article.

\section{Correspondence to}

Dr Isabella Joy Robbins; isabella.robbins@nottingham. ac.uk

\section{ABSTRACT}

Objective: To explain the current delivery of healthcare to residents living in UK care homes.

Design: Qualitative interview study using a grounded theory approach.

Setting: 6 UK care homes and primary care professionals serving the homes.

Participants: Of the 32 participants, there were 7 care home managers, 2 care home nurses, 9 care home assistants, 6 general practitioners (GPs), 3 dementia outreach nurses, 2 district nurses, 2 advanced nurse practitioners and 1 occupational therapist.

Results: 5 themes were identified: complex health needs and the intrinsic nature of residents' illness trajectories; a mismatch between healthcare requirements and GP time; reactive or anticipatory healthcare?; a dissonance in healthcare knowledge and ethos; and tensions in the responsibility for the healthcare of residents. Care home managers and staff were pivotal to healthcare delivery for residents despite their perceived role in social care provision. Formal healthcare for residents was primarily provided via one or more GPs, often organised to provide a reactive service that did not meet residents' complex needs. Deficiencies were identified in training required to meet residents' needs for both care home staff as well as GPS. Misunderstandings, ambiguities and boundaries around roles and responsibilities of health and social care staff limited the development of constructive relationships.

Conclusions: Healthcare of care home residents is difficult because their needs are complex and unpredictable. Neither GPs nor care home staff have enough time to meet these needs and many lack the prerequisite skills and training. Anticipatory care is generally held to be preferable to reactive care. Attempts to structure care to make it more anticipatory are dependent on effective relationships between GPs and care home staff and their ability to establish common goals. Roles and responsibilities for many aspects of healthcare are not made explicit and this risks poor outcomes for residents.

\section{INTRODUCTION}

Around 423000 care home places are provided by the private and voluntary sector in England and Wales. ${ }^{1}$ Ninety-one per cent of

\section{ARTICLE SUMMARY}

Article focus

- Care home residents suffer from long term comorbid conditions, with acute deteriorations, rendering them disabled and vulnerable.

- There is a growing body of evidence that care home residents have unmet health needs and may be admitted to hospital unnecessarily.

- This study aimed to understand healthcare delivery to care home residents from both the care home and primary care perspectives, in order to explain why hospital admissions occur and to identify where the barriers and solutions in improving healthcare lie.

Key messages

- Both general practitioners as well as care home staff described that care for residents was affected by inadequate training, insufficient time and uncertainty about who from health and social care sectors held responsibility for key aspects of healthcare provision.

- Care home staff played an important, yet little recognised, role in delivering healthcare to residents. They did this through contributions to observation, shared decision making and by mediating access to both primary and secondary healthcare.

- Primary healthcare was not organised to deliver effective healthcare to meet the needs of care home residents. It was predominantly ad hoc and reactive and, as such, was poorly placed to anticipate either gradual or acute deterioration in a way that would facilitate proactive management.

Strengths and limitations of this study

- The study considered accounts from both health and social care staff. This allowed us to recognise the commonalities in the challenges described by health and social care staff and their shared understanding of the role that social care staff play in healthcare delivery.

- Patient and family carer perspectives were not explored and the study was therefore unable to comment on the patient-user perspective of healthcare for care homes.

residents are over 70 years old, $78 \%$ have at least one form of mental impairment and $76 \%$ require assistance with mobility or are 
immobile. ${ }^{2}$ There is growing evidence that care home residents have unmet health needs, ${ }^{3-7}$ may be admitted to hospital unnecessarily ${ }^{8}$ and that their dignity may be affected by poor access to healthcare. ${ }^{9}$

Primary healthcare provision, in UK care homes is coordinated by general practitioners (GPs), supported by district nurses and a team of community-based allied health professionals. This provision should be identical to that for individuals living in their own homes, but is in contrast to the situation in the USA and the Netherlands where there is care home-specific healthcare provision. ${ }^{10}$ Existing mechanisms for quality assurance of healthcare may fail to meet the needs of care home residents. The Quality Outcomes Framework (QoF), used by the National Health Service (NHS) to ensure that primary care across the UK is systematic and evidence-based, does not address residents' needs. ${ }^{11}$ Meanwhile, the regulator of care homes, the Care Quality Commission (CQC), has primarily focused on the quality of social care provision. ${ }^{12}$ When the CQC did turn its attention to healthcare, with a recent national survey, it reported that residents were often not informed of the healthcare arrangements for the home, and that for nearly half $(44 \%)$ there was no regular GP visit to the home. ${ }^{13} 14$

This study set out to contribute to the debate on how to improve healthcare in care homes by understanding why healthcare provision is such a cause for concern when commissioners believe that they have put adequate services in place. In order to do this we needed to find out what actually happens when a care home resident needs healthcare and why the processes that take place occur. We needed to understand the underlying facilitators and barriers in achieving the best and most appropriate healthcare for patients. From such an understanding, recommendations could then be made for the design of future provision.

\section{METHOD}

\section{Methodological approach}

With the existing paucity of knowledge concerning how healthcare is delivered in care homes, a grounded theory approach ${ }^{1516}$ was adopted.

A phenomenological interview study was used to understand how formal healthcare was delivered in care homes. The perspectives of care home staff and primary care services were sought using qualitative interviews which aimed to provide a description of context, different cultures of work, concepts and behaviours ${ }^{16} 17$ and to give parity to accounts from different professional and organisational perspectives.

Semistructured interviews were used, expecting respondents' time to be limited. In light of the media and regulatory scrutiny, it was anticipated that care home staff might feel defensive and that their care was being judged. Therefore a hypothetical case vignette (box 1) was used to help elicit talk and to generate valid data.

\section{Sampling strategy}

The initial intention was for both residential and nursing homes, with and without dementia registration, to be sampled. The aim was to sample participants from the typical range of care staff who work in care homes and from primary care. Initial interviews were therefore planned with managers, nurses and care assistants employed in care homes and GPs, district nurses and allied health professionals providing services from primary care. The data-driven grounded theory approach required theoretical sampling whereby sampling decisions could change as the study progressed, in order to test evolving theoretical constructs.

\section{Recruitment}

As part of the National Institute for Health Research (NIHR)-funded Medical Crises in Older People research programme (http://www.nottingham.ac.uk/mcop/ index.aspx), the managers of all care homes within Nottinghamshire and a 10-mile radius of the University of Nottingham Medical School $(n=131)$ were invited to a care home educational event. Of these, 18 care homes accepted an invitation to take part in a cohort study. ${ }^{18}$ Eleven care homes were selected from these for the cohort study using a purposive sampling matrix which reproduced the proportion of residents housed in residential/nursing and dementia registered homes nationally. All 11 homes from the cohort study were invited to take part in the interview study. Once the home was recruited, individual care home staff were invited to participate through a circular letter and posters placed in staff rooms and on notice boards. Data saturation was reached after six homes were recruited.

GPs were approached after recruitment of the care home. One practice attached to each home was identified and GP who most frequently provided care was approached. Allied health professionals and district nurses were recruited from contacts made during the conduct of research in GP practices and care homes, or sought out by telephone and letter where their participation was considered to be important to the emerging theoretical framework.

\section{Box 1 The vignette}

Imagine a resident who is short and stooped with a curved spine. She suffers from stiff, painful joints. She is thin. She becomes muddled and disorientated from time to time. She usually needs some help with personal care and wears a small pad for urinary incontinence-a little leakage. She keeps getting urinary tract infections. She has long spells when she is well, but when she gets an infection, staff notice changes in her. She starts to become more confused, so that she needs more help with her personal care than usual. She becomes a bit more unsteady on her feet. The last time that this happened, she had a brief emergency visit to hospital and it took a week or two for her to get back to normal. Can you think about your own experience and recount a similar case? 


\section{Interviews}

The interviews were completed at a time and place to suit the participants and lasted between 20 and $90 \mathrm{~min}$. An interview guide (see online supplementary appendix) and case vignette (box 1) guided the interview. Recordings were made using a digital recorder and transferred to compact discs, transcribed and anonymised. The recordings were erased as soon as the anonymised transcription was verified as a true record by the interviewer.

The interviews were undertaken by IJR and ALG. Neither had direct clinical responsibility for the residents in the care homes, but ALG worked as an NHS community geriatrician in the same region.

\section{Analysis}

To understand the complexity of healthcare delivery, an iterative process ran in parallel with data collection. After each interview IJR and ALG discussed the interview content which they checked against interview schedules. The schedules were adapted, with emerging themes to be used in later interviews. Memos were written after interviews, recording ideas and initial analysis. Contradicting evidence was sought in the emerging theories. Recruitment was stopped when data saturation was felt to have been reached. Further analysis was performed using NVivo V.8 to organise the interview data and memos. Coding of all the data was carried out by IJR and ALG, independently initially, to develop subthemes. The final analysis was triangulated by all authors through team discussions, literature review and the writing phase of this process.

Quotes from participants are identified using the following abbreviations: CHM, care home manager; CA, care assistant; GP, general practitioner; $\mathrm{TN}$, trained nurse; ANP, advanced nurse practitioner; Res, residential care home; Nurs, care home with nursing; Dual, dual registered home (residential and nursing).

\section{RESULTS}

\section{Sample}

The participating care homes are described in table 1 . All of these were dementia registered. Two had formal healthcare provided by a single GP practice, with whom all residents were registered. The remaining homes had relationships with multiple practices. None of the homes had private contractual arrangements with GPs.

Early in the course of the analysis, the relationship between care home managers and GPs emerged as pivotal in the delivery of all aspects of healthcare. In line with theoretical sampling we therefore sought out more participants from these two groups as the study progressed in an attempt to better understand these relationships. Likewise fewer participants from the wider primary care team were sought. Thirty-two interviews were conducted: seven care home managers (one home had a different manager for its residential and nursing and both were recruited), two care home staff nurses, nine care assistant, six GPs (one for each home), three members of dementia outreach teams, two district nurses, two advanced nurse practitioners and one occupational therapist.

\section{Coding framework}

The accounts offered by participants helped build a picture of healthcare that took place as a composite of the formal contributions of health professionals and the less formal work of care home staff. The provision of formal healthcare was, for the most part, driven by unanticipated deterioration in residents' health status, rather than being anticipatory or preventative. The care given by the care home staff, although often labelled as social care, was commonly targeted at health problems or at the maintenance or restoration of health. All participants expressed concern for residents and patients, acknowledging the considerable challenges of caring for frail older people at the end of their lives but attributing shortcomings to aspects of the system, rather than the residents or patients themselves.

The main themes of the analysis (table 2) explain why there are such shortcomings and uncovered barriers to providing effective healthcare in care homes.

Analytic themes were finally expanded and organised under the following headings:

- Complex health needs and the unpredictable nature of residents' illness trajectories.

- A mismatch between healthcare requirements and GP time.

- Reactive or anticipatory healthcare?

- A dissonance in healthcare knowledge and ethos.

- Tensions in the responsibility for the healthcare of residents.

\section{Table 1 Profile of participating care homes}

\begin{tabular}{lllll}
\hline & Type of care home & Type of ownership & Number of residents & Location \\
\hline 1 & Residential with dementia care & Charity & 38 & Urban \\
2 & Nursing and residential with dementia care & Private small chain of homes & 42 & Suburban \\
3 & Residential with dementia care & Owner/manager & 25 & Suburban \\
4 & Nursing with dementia care & Owner/manager & 40 & Rural \\
5 & Nursing with dementia care & Owner/manager & 27 & Rural \\
6 & Residential and nursing with dementia care & Private & 30 & Suburban \\
\hline
\end{tabular}


Table 2 Coding and analytic framework

\begin{tabular}{|c|c|}
\hline Main themes & Subthemes \\
\hline Healthcare issues & $\begin{array}{l}\text { Acuity of residents, complex comorbidities } \\
\text { Best interests: dementia and capacity } \\
\text { Deterioration or rehabilitation } \\
\text { Emergency care } \\
\text { Access to medical care } \\
\text { Anticipatory care } \\
\text { Frailty } \\
\text { Residential versus nursing status }\end{array}$ \\
\hline $\begin{array}{l}\text { Professional boundaries as barriers to } \\
\text { delivering care }\end{array}$ & $\begin{array}{l}\text { Not calling the GP } \\
\text { Deference } \\
\text { Expert vs tacit knowledge } \\
\text { Role and disempowerment } \\
\text { Recognising change } \\
\text { Best interests } \\
\text { Relationships/family } \\
\text { Social care }\end{array}$ \\
\hline Risk & $\begin{array}{l}\text { Distinguishing between minor and catastrophic symptoms } \\
\text { Moral and legal tensions: who takes responsibility for healthcare decisions }\end{array}$ \\
\hline Responsibility & $\begin{array}{l}\text { Care homes as the last refuge when neither family or NHS can/will take on care } \\
\text { An ethic of care (moral ought) } \\
\text { Care staff skill, disempowerment and responsibility }\end{array}$ \\
\hline $\begin{array}{l}\text { Home or hospital-where should } \\
\text { the care be delivered? }\end{array}$ & $\begin{array}{l}\text { Stranger at the bedside-hospital care that inevitably means people who do not } \\
\text { know the residents caring for them } \\
\text { The absence of end of life planning and care } \\
\text { "Give her a chance" } \\
\text { Substandard care (hospital): the experience of care home residents sometimes } \\
\text { returning to the care home more ill than when they went } \\
\text { "We're not short of work" (GPs) } \\
\text { Support for care home staff in caring for ill residents }\end{array}$ \\
\hline Expectations and tensions & $\begin{array}{l}\text { Normative assumptions of care homes as businesses/poor care (NHS staff) } \\
\text { Care homes held at arm's length } \\
\text { Dealing with end of life } \\
\text { "Oh God you know they've got septicaemia" (social care practitioners as healthcare } \\
\text { practitioners) }\end{array}$ \\
\hline Contradictions & $\begin{array}{l}\text { The economy of care: untrained staff in care homes and GP time } \\
\text { Ethic of care vs business ethic (both care home managers and GPs refer to the } \\
\text { economy of their work) } \\
\text { Deontological ethics vs consequentialist ethics: end of life (moral and legal tensions) }\end{array}$ \\
\hline Consequences & $\begin{array}{l}\text { Care homes in isolation } \\
\text { Formal healthcare at a distance } \\
\text { Care homes as a last resort, "picking up the pieces" } \\
\text { Residents waiting for healthcare } \\
\text { Reactive healthcare } \\
\text { Quality of life? }\end{array}$ \\
\hline
\end{tabular}

GP, general practitioner; NHS, National Health Service.

Complex health needs and the unpredictable nature of residents' illness trajectories

Several participants suggested that the health profile of care home residents has shifted over the recent past. Nursing home residents now resemble those previously cared for in long stay hospitals, and residential home occupants those previously cared for in nursing homes.

Well I mean, I think the main changes people who have got, become more dependent, I mean hugely dependent, whereas, I mean when Kimpton Lodge opened most people could walk independently some would use zimmer frames. We didn't have anybody initially that needed hoisting. We bought our first hoist in '91 and that's sufficed for about 10 years I think it was. And now we've got hoists coming out of everywhere. I mean we just haven't got the space to store them basically. (Care home manager 5)

Participants suggested that higher levels of support in the community were a key reason for the increasing dependency of the cohort as a whole. 
But I think the big change in the last ten years is that we are taking people into care homes much further on into their dementia than we ever used to. Because people are being cared for much longer at home with good care packages going in, lots of family support... So I think that's helpful but I think we are getting people coming in, you know, much more moderate to advanced than we ever used to, so care homes are filling up with quite dependent, quite challenging people. (Outreach dementia care team)

All of the participants argued that the health profile of care home residents has shifted significantly over the recent past. Nursing home residents now resemble that of long stay hospital patients (no longer in operation), and residential home occupants that of nursing home residents. Care homes residents were perceived to experience complex illnesses with high levels of health and social need. Although the vignette used in the interview referred to a minor illness in a presumed long-standing resident, participants often raised admission to the care home as a particularly difficult time.

\begin{abstract}
We've got a lady about to be admitted to us, she's obese, lymphodema, chronic obstructive airways disease, continuous oxygen, they've put in a caecostomy tube, she's catheterised, she's in bed, she's feeling nauseous all the time, she's hasn't been out of bed for 5 months, as far as I'm aware she hasn't got any pressure sores but she does tell me that her bottom's very sore. (CHM4Nurs)
\end{abstract}

Ongoing healthcare of residents, of the sort discussed in the interview vignette, was recognised as part of the core work of both care home staff as well as GPs. All participants, from health professional as well as social care backgrounds, found it difficult and challenging at times, to interpret the significance of changes in the symptoms of residents who usually had multiple and chronic health conditions.

I had one of my residents admitted last week to hospital with, and we thought she'd had a stroke. It was a UTI. (CHM1Res)

Participants also frequently spoke of death and dying as being difficult to predict.

Because one day, they can be fine, the next day, they stop eating, and then they could linger for months, or the next day, they could die. (GP3)

She seemed alright, and all of a sudden she had a funny turn during tea, and so we put her in a wheelchair as quick as we could to get her out of sight from the others you know, because they can't understand what's happening and it upsets some people, and we put her in her bedroom, and we had to dial 999 and the lady actually died before she got to hospital. (CA5Res)

Participants reported the negative effect of poor information transfer to care homes, particularly around admission and discharge from hospital. There was a mistaken expectation held by hospital staff that further management and additional healthcare such as speech and language therapy, occupational therapy and physiotherapy would be easily accessible to care homes.

For newly admitted residents, transfer of patient notes from one GP to another could be delayed for weeks, delaying crucial information for safe care and management.

... Complete disaster, when she moved into the home, took us ages to get hold of ... her old records. And the staff at the home thought she'd got diabetes. But in fact she had diabetes insipidus ... (GP1)

There was a mismatch in healthcare requirements and GP time. GPs described visits to care home residents taking up a substantial amount of their workload.

$10 \%$ of our elderly patients are in care homes, and $10 \%$ of our population are over $75 \ldots$ we have at least two to three out of the average of 10 visits a day are to care homes (GP3)

Two patterns of primary care organisation were evident in our data. The residents of the two rural care homes were served by single GPs, whereas the urban homes were served by several GPs from local general practices. Having a one-to-one relationship with a single GP in rural care homes arose out of geographical necessity and was praised by all respondents for one home while being roundly criticised in the second example. For the former, a constructive working relationship was described, defined by frank and open discussion of differences around patient care and a history of joint initiatives between the GP and care home to improve healthcare for residents.

Because we do it that way, we do get to know the patients...one GP practice covering the whole nursing home, I think also works because the nurses know what to expect when they call the doctors. I mean, they know us and we know them. (GP4)

The relationship at the second home was defined by mistrust, conflict and reluctance on behalf of both care home staff and GP to engage with each other. The sense was that a one-to-one relationship would not have been chosen were it not for the geographical necessity.

Yes they [the care home] are hard work...all the other GP's have said, 'No,' so we are lumbered with it. What we did propose was that we have half the patients in [the village] and let's have half the nursing home people, but no, all the practices have turned round and said, 'No, it's not in our area'. Of course it's in their area...(GP5)

Multiple GPs assigned to each care home, and reports of the variable attitudes and skills of GPs, made communication and developing relationships problematic. 
We have seven GP surgeries looking after our residents... well sometimes I'll pick up the phone and I'll speak to a GP, I don't recognise your name doctor, are you new there? (CHM2Dual)

The suburban GPs in our sample could see some advantages in organising a one-to-one relationship in terms of facilitating a relationship with care home staff and getting to know their patients better. But they also perceived barriers to this approach in the form of patient choice and organisational issues with neighbouring practices.

it's a relatively new home that...started about three or four years ago in the area, and what we're doing with them is we've actually said to them, we're prepared to take on ten of your patients but after that, it becomes too much of a sort of, too much of a burden really, because it's a, it's a specialist dementia home and they're very difficult management-wise (GP1)

\section{Reactive or anticipatory healthcare?}

The rural care home in our sample with an effective one-to-one relationship with the GP had regular scheduled visits to the home. These were perceived to enable efficient, anticipatory care and reduce out-of-hours care. However, the remainder of the homes studied did not have regular scheduled visits from their GPs. Two of the urban GPs had previously attempted to establish these types of arrangements with local care homes but had abandoned the custom, concluding that it had no effect on calls from the home between scheduled visits.

In the past, we used to try and do anticipatory things like a little ward round once a week. And I think we just found that it wasn't making a lot of difference to just letting the staff call us when they needed help. So we were putting more hours in without seeing very much for it. (GP1)

For some care home managers the concept of weekly visits was unhelpful because they considered that their residents sometimes fell ill without warning, and it was at these times they required support.

two weeks ago one of the doctors sent a letter...saying that the doctor gets called out on numerous days for minor issues, and they want to come just once a week, so I phoned up the practice manager and said, 'I cannot tell you when a resident is going to be ill, that's fine, I'll call an after hours' doctor out, you'll get charged.' So they know they have to visit, when I want a doctor, a doctor comes. (CHM6)

Given the reliance on a system where care homes called GPs reactively, care home staff were concerned when access to primary care was poor and slow.

There is always a time limit sometimes you have to call before 10 , but if something like that after $10 \mathrm{I}$ have to do it myself because I have to use my charm again with the [receptionist] there, so that they can book it immediately. So I just have to say, 'I know I'm a bit late, but you see it's a bit of an emergency here'. (CHM2Dual)

Efforts to protect GP time were made. For example, some homes accumulated individual issues for the GP to attend to in one visit and one care home manager took residents to the surgery if their condition allowed. Although well intentioned, these practices could have serious implications for residents' well-being.

Somebody was almost moribund when I went to see them, and you know, the visit had been put through to reception as just a routine sort of unwell sort of thing, the receptionist hadn't realised quite how unwell, just put it down for a routine visit. (GP2)

\section{A dissonance in healthcare knowledge and ethos}

Staff in care homes, which are social care institutions, are trained at least to meet the minimum standards of social care required by regulation. It was obvious to care home staff that this did not equip them to deal with the healthcare needs of their residents.

Some of our residents do have some really complex healthcare needs and, and obviously, because we're not a registered nursing home and we're not healthcare professionals, we're really dependent on the service we get from GPs, (CHM1Res)

Some GPs highlighted a link between social care training and the inability to identify healthcare problems, with consequences upon residents' well-being and GP time.

The staff particularly in a residential home, are not trained medically so they, they might see there's a bit of a change in a resident but think, 'Oh well, they're just having a bad day today, we'll wait a little bit longer.' And that, you know, we kind of want them to do...It's difficult to get the balance right...very difficult...for them to try and anticipate when people are becoming ill and call us in to pick things up earlier. (GP1)

Healthcare staff often attributed what they considered to be inadequate training of care home staff to the 'profit motive' of care homes operating in the private sector.

But they're privately employed and there's always, there's always these issues, isn't there, about, I suppose, well, as a, what you read in the papers, there's always the issue about owners wanting the maximum profit, and therefore the minimum staffing and all the rest of it. (GP2)

Despite this, GP training and skills were also felt to be inadequate, or as one GP candidly put it.

The average General Practitioner isn't experienced enough... and you need a, basically another specialism 
going in and I think that would deliver better care to the patient.(GP5)

Despite the concerns of GPs that care home staff lacked healthcare skills, care home staff revealed a body of experientially derived health-related knowledge. Examples included nutrition, rehabilitation or the identification of new illnesses.

So we've got him on the, we tried the hoist and he was okay and then, they had to stand him, and I said, 'Could he stand?' and they said 'Yes.' I said, 'Right, don't use the hoist, get the rotunda out, two of you, and do him on that.' So he's going to gain that little bit of strength, isn't he? (CHM3Res)

\section{Tensions in the responsibility for the healthcare of residents}

A recurring issue in both the nursing and dualregistered homes was the ambiguous nature of what care should be provided by care home nurses and what should be provided by NHS district nursing services.

As a district nurse is a bit of an issue, because there are times when we have to go into a residential home to administer insulin when there are nurses there, trained nurses, and they will not administer the insulin because they're saying we're not insured, so that piles even more pressure, even more visits onto the district nurses. (DN1)

Some care homes recognised that they could provide more healthcare and that it would be beneficial to residents if they did so, but expressed a strong fear of being blamed for mistakes.

At the back of your mind you always know that if there's a deterioration in somebody's condition, if there's a medical change, we would be neglectful if we just sat there and recognised that, and thought oh we'll get the doctors to see it next Tuesday. (CHM2dual)

Legislation and regulation sets out standards for care home managers. There was an understanding by managers that, as part of their responsibility for residents' well-being, they would ultimately be held responsible for residents' health as well as their social welfare. They therefore saw mediating access to healthcare as part of their role.

Obviously, being a registered manager, you're legally responsible for an awful lot for, under the care homes regulations act, care standards act. (CHM1)

This perceived responsibility for healthcare decisions extended to end of life issues, which were universally considered to be difficult. Some care home managers described tackling the issue of do not attempt resuscitation (DNAR) orders directly with residents and families and having to take important decisions about advance care planning without support from healthcare professionals.

Social services don't want the family to make that [do not resuscitate] decision. So I'm in the middle here, because if you don't do it means you're neglecting it, you're not good a nurse, you're not a good home, but the GP does not want to take responsibility for that. (CHM2)

There was a mismatch between care home managers' expression of responsibilities bounded by duty of care and fear of regulation and NHS staff's frequent assertion that fear of litigation influenced how care homes undertook their work.

\begin{abstract}
Although they're writing 'today Bill', for example, 'refused a bath, was too ill to get in the bath and just wanted hands and face washed', documenting it but the care plan says Bill is able to make a, is able to have a bath or shower each day. So that would not stand up in a court of law if it had to. (ANP1)
\end{abstract}

GPs often reported not liking this work. One of their main concerns, attributed to poor staff skills and hence risk assessment was that some patients were referred to them for what they considered to be, trivial reasons.

the leg's a bit red, or something like that, and you know you can see from looking at the notes that your colleague's been that week, said it might be a mild cellulitis, not too bad, probably give some antibiotics, but you know let's not worry too much about it, leg's not better come back and visit again. Hang on a minute you haven't given it long enough (GP4)

GPs also expressed concern regarding the value of medical intervention in many of the residents.

A person who's in a home, it's the end of their life. They become ill, they get a chest infection, are we going to treat them? Are we going to bother? Do they want to go into hospital, be messed around, needles stuck in them, people messing them about? You know, isn't it better they just died? (GP1)

Despite their limited healthcare skills, care home staff are responsible for accessing healthcare and felt they have important contributions to make to healthcare decisions. However, inadequate working relationships with primary care staff prevented them from doing so. This was particularly evident in their role as advocate for the residents, most of whom they knew well and with whom they had close relationships-at times accepting a role comparable to kinship for those with no family. The particular contributions they described related to assessments of mental capacity for medical decisions and in establishing the best interests of residents.

A lady...with advanced dementia, a succession of chest infections and asthmatic. GP wanted [this lady] to be 
admitted into hospital. The nurse didn't think it was in this lady's best interests...she was treated with IV antibiotics, she came out of hospital. She died eight days later. (TN2)

\section{DISCUSSION}

The study set out to describe facilitators and barriers in providing best-quality healthcare for care home residents. The findings not only presented under the five main headings that provide a summary of these but also contribute to an understanding what might be seen to comprise good healthcare in this setting.

The findings presented under complex health needs and the unpredictable nature of residents' illness trajectories, suggest a patient cohort defined by dependence added to complexity and considerable clinical fluctuation, which it is difficult to predict. Respondents from all disciplines found this challenging. This recognition that much of the difficulty in dealing with residents comes from the complexity of their conditions, represents an important starting point for constructive approaches to healthcare provision. The failure to provide timely and comprehensive medical information was a recurrent observation which seemed to confound these difficulties and is a legitimate target for quality improvement.

Under mismatch between healthcare requirements and GP's time there was a broad consensus that good care for such complex residents takes time, which many GPs were unable to make. Further discussions focused on how care is, or ought to be, structured. The most positive descriptions of healthcare came from a home with a 1:1 relationship with a GP but so did the most negative. Such relationships would seem to be able to facilitate highquality care where the home and GP are suitably and mutually engaged and can establish common goals. They can clearly be destructive when these conditions are not met.

Considering reactive versus anticipatory care, the latter seemed to be an ambition for most respondents. For many, this was fostered out of frustration at the negative consequences of reactive care, rather than experience of anticipatory care models which had been seen to work. Some spoke positively of the role that regular scheduled GP visits could play but it was clear that this should not be proposed at the exclusion of rapid response between scheduled visits, given the unpredictable illness trajectories already discussed.

The dissonance between healthcare knowledge and ethos seemed to be located as much in perception as reality. Once again health and social care staff seemed to describe common, rather than separate, challenges. Both described deficiencies in their own and each others' training. It was clear that, with very few exceptions, staff from all sectors felt inadequately prepared and resourced to care for residents and that more expertise was desired.

Finally, under tensions in the responsibility for healthcare of residents, care home managers and staff described vividly how they often played a coordinating role in both delivering and mediating access to healthcare for residents. They also described uncertainty as to where this role sat within existing regulatory frameworks, being driven more by duty of care than specific guidance. This uncertainty could lead to deficiencies in care, where neither healthcare staff or GPs were clear on who should take primary responsibility for, as an example, anticipatory care planning.

Previously the care home population has not been well described, although this has been accomplished in the recent past. $^{2} 18$ This study goes beyond description and qualitatively explains how care homes experience the high degree of dependence and illness the care home population now represents and the mismatch between healthcare need and healthcare provision. Wide variation in GP provision to care homes ${ }^{5-8}$ and difficulties in delimiting the role of care home staff ${ }^{19}$ have both been described in previous studies. Former studies in this area ${ }^{20-22}$ have identified that care home staff feel that their priorities and expertise are not acknowledged. Our study not only confirms this but also shows how it can affect the healthcare of residents-for example, in the formulation of end-of-life care planning. However, by considering the question of healthcare delivery to residents from both perspectives we have added to this understanding by recognising the commonalities in many of the challenges described. These commonalities were not often recognised by interviewees. Failure to recognise common ground contributes to the difficulty of relationships between care home managers, senior care home staff and GPs. This may be a consequence of inadequate partnerships and integration between the (publicly funded) health service and the (private) care home sector.

The main strength of this study is that it considered the perspectives of both health and social care staff and studied dyads of health and social care providers. This allowed a balanced account of the provision of healthcare to care homes to be established. There were a few limitations. The study was conducted in a single region and so cannot be taken as representative of the situation across all of England, or the UK as a whole. It also did not take account of the perspective of patients or family carers. While this was rationalised on the basis that these groups would have a limited insight into the practicalities of healthcare, as negotiated between health and social care providers, it does mean that a potentially useful perspective was omitted.

In conclusion, on the basis of these findings, a large part of the challenge of providing effective healthcare to care home residents comes from the complexity of the medical problems presented by the residents themselves. Their healthcare needs would be more effectively met by models of care which provide health and social care staff with specific training in anticipating and managing fluctuations in health status; ensure effective transfer of adequately detailed information at the point of arrival to 
and departure from a care home; provide sufficient time for assessment and management of health problems as a routine; and provide explicit lines of responsibility for particular aspects of healthcare management.

\section{Author affiliations}

${ }^{1}$ Division of Rehabilitation and Ageing, Queens Medical Centre, School of Community Health Sciences, University of Nottingham, Nottingham, UK ${ }^{2}$ NIHR Research Design Service-East Midlands, School of Community Health Sciences, University of Nottingham, Nottingham, UK

Acknowledgements We would like to thank the care home staff, general practitioners and allied health professionals who took part in this study.

Contributors IR and AG contributed tostudy design, conducted the interviews, analysed results and wrote the initial draft ofthe manuscript. IR acts as the guarantor. JD contributed to study design, and played a contributory and coordinating role in the analysis of results and write-up. PL and JG contributed to study design, analysis and write-up.All authors have read and approved the final version of the manuscript.

Funding This article presents independent research commissioned by the National Institute for Health Research (NIHR) under its Programme Grants for Applied Research funding scheme (RP-PG-0407-10147). The British Geriatrics Society provided a Specialist Registrar start-up grant in support of $A L G$ at the outset of this project.

Competing interests None.

Ethics approval Ethical approval was gained from the local National Health Service (NHS) ethics committee (REC 09/H046/82).

Provenance and peer review Not commissioned; externally peer reviewed.

Data sharing statement No additional data are available.

\section{REFERENCES}

1. Laing and Buisson. Care of elderly people UK market survey. 22nd dn. Laing and Buisson Ltd, 2009.

2. Bowman $\mathrm{C}$, Whistler J, Ellerby M. A national census of care home residents. Age Ageing 2004;33:561-6.

3. British Geriatrics Society A Quest for Quality Joint Working Party Inquiry into the Quality of Healthcare Support for Older People in Care Homes: a Call for Leadership, Partnership and Quality Improvement. 2011. http://www.bgs.org.uk/campaigns/carehomes/ quest_quality_care_homes.pdf (accessed Mar 2012).

4. Care Quality Commission Health care in care homes: a special review of the provision of health care to those in care homes. March 2012. http://www.cqc.org.uk/sites/default/files/media/documents/ health_care_in_care_homes_cqc_march_2012.pdf (accessed Apr 2012).
5. Heath $\mathrm{H}$, Health and Health care Services My Home Life Quality of life in care homes: a review of the literature. 2007:96-116. http:// www.scie.org.uk/publications/guides/guide15/files/myhomelifelitreview.pdf (accessed Feb 2012).

6. Barodawala S, Kesavan S, Young J. A survey of physiotherapy and occupational therapy provision in UK nursing homes. Clin Rehabil 2001;15:607-10.

7. Glendinning $C$, Jacobs S, Alborz A, et al. A survey of access to medical services in nursing and residential homes in England $\mathrm{Br} J$ Gen Pract 2002;52:545-8.

8. Bowman CE, Elford J, Dovey J, et al. Acute hospital admissions from nursing homes: some may be avoidable. Postgrad Med $\mathrm{J}$ 2001;77:40-2.

9. NHS Confederation Delivering Dignity: Securing dignity for older people in hospitals and care homes. A report for consultation. 2012. http://www.nhsconfed.org/Documents/dignity.pdf (accessed Jun 2012).

10. Conroy S, Van Der Cammen T, Schols J, et al. Medical services for older people in nursing homes-comparing services in England and the Netherlands. J Nutr Health Ageing 2009;13:559-63.

11. Shah SM, Carey IM, Harris T, et al. Quality of chronic disease care for older people in care homes and the community in a primary care pay for performance system: retrospective study. BMJ 2011;342:912.

12. Care Quality Commission. About us care homes. 2011. http://www. cqc.org.uk/public/about-us\#carehomes (accessed Jan 2012).

13. Care Quality Commission Meeting the Health care needs of people in Care Homes. March 2012. http://www.cqc.org.uk/public/reportssurveys-and-reviews/reviews-and-studies/meeting-health-careneeds-people-care-homes (accessed Apr 2012)

14. Royal College of Physicians, Royal College of Nurses, British Geriatrics Society Health and care of older people in care homes: a comprehensive interdisciplinary approach 2000 RCP London.

15. Glaser BG, Strauss A. The discovery of grounded theory strategies for qualitative research. New York: Aldine, 1968.

16. Murphy E, Dingwall R. Qualitative methods and health policy research. New York: Aldine de Gruyter, 2000.

17. Pope C, Mays N. Reaching the parts other methods cannot reach: an introduction to qualitative methods in health and health services research. BMJ 1995;31:1-46.

18. Gordon AL, Franklin M, Bradshaw L, et al. Health status of UK care home residents-a cohort study Age and Ageing 2013. In press.

19. Perry M, Carpenter I, Challis D, et al. Understanding the roles of registered nurses and care assistants in UK nursing homes. J Adv Nurs 2003;42:495-505.

20. Davies SL, Goodman C, Bunn F, et al. A systematic review of integrated working between care homes and health care services. BMC Health Serv Res 2011;11:320.

21. Goodman C, Davies S, Norton C, et al. Collaborating with primary care: promoting shared working between district nurses and care home staff. In: Froggat K, Davies S, Meyer J. (eds) Understanding care homes: a research and development perspective. Jessica Kingsley Publishers, 2009:201-22.

22. Seymour JE, Kumar A, Froggatt K. Do nursing homes for older people have the support they need to provide end-of-life care? A mixed methods enquiry in England. Palliat Med 2011;25:125-38. 